Research Paper

\title{
Clinical study on the prevalence and comparative analysis of metabolic syndrome and its components among Chinese breast cancer women and control population
}

\author{
Yu-tuan $\mathrm{Wu}^{1 *}$, Qing-qing Luo ${ }^{1 *}$, Xin $\mathrm{Li}^{1 *}$, Bilal Arshad ${ }^{1 *}$, Zhou $\mathrm{Xu}^{1 *}$, Liang Ran ${ }^{2}$, Chun-xia Zhao ${ }^{1}$, He $\mathrm{Wu}^{1}$, \\ Yan-ling Shi ${ }^{1}$, Hao-ran Chen ${ }^{1}$, Hao Li $^{1}$, Hong-yuan $\mathrm{Li}^{1}{ }^{1}$, Kai-nan $\mathrm{Wu}^{1}{ }^{1}$, Ling-quan Kong ${ }^{1 凶}$ \\ 1. Department of Endocrine and Breast Surgery, the First Affiliated Hospital of Chongqing Medical University, Chongqing 400016, China; \\ 2. Department of Physical Examination, the First Affiliated Hospital of Chongqing Medical University, Chongqing 400016, China. \\ * These authors contributed equally to this work. \\ $\square$ Corresponding author: Ling-quan Kong, e-mail: huihuikp@163.com, Department of Endocrine and Breast Surgery, the First Affiliated Hospital of Chongqing \\ Medical University, No.1 You Yi Rd., Chongqing 400016, China. \\ (c) Ivyspring International Publisher. This is an open access article distributed under the terms of the Creative Commons Attribution (CC BY-NC) license \\ (https://creativecommons.org/licenses/by-nc/4.0/). See http://ivyspring.com/terms for full terms and conditions.
}

Received: 2017.09.24; Accepted: 2017.11.10; Published: 2018.01.01

\begin{abstract}
Metabolic syndrome has been previously identified as a risk factor for breast cancer and is increasingly a public health concern. This study aims to investigate the prevalence of metabolic syndrome and its components among primary breast cancer and control population. The clinical data of metabolic syndrome and its components in the breast cancer (605 cases) and control population (3212 cases), from Breast Cancer Center and Physical Examination Center of Chongqing, China, from July 2015 to February 2017, were collected for comparative analysis. This study was prospectively registered in Chinese Clinical Trial Registry (http://www.chictr.org.cn/, number: ChiCTR-OOB-15007543). The prevalence of metabolic syndrome in breast cancer $(32.6 \%)$ was obviously higher than that in control population (18.2\%) ( $p<0.001$; OR: $2.173,95 \% \mathrm{Cl}: 1.793$ to 2.633 ). With age stratification, the prevalence of metabolic syndrome in breast cancer group aged below 60 years $(24.9 \%, \mathrm{p}<0.001$; OR: $2.216,95 \% \mathrm{Cl}$ : 1.744 to 2.816) and equal/above 60 years (58.3\%, $\mathrm{P}<0.001$; OR: $2.291,95 \% \mathrm{Cl}$ : 1.580 to 3.322 ) were also statistically higher than those (13.0\% \& $37.9 \%)$ in control population, respectively. Breast cancer women were more likely to have preobese (BMI 25.0-29.9) or obesity (BMI $\geq 30.0$ ), broader waist circumference, lower HDL-C level, higher systolic and/or diastolic blood pressure and higher fasting blood glucose level compared to the control population, corresponding prevalence were $31.7 \%$ vs. $19.4 \%, 76.0 \%$ vs. $29.6 \%$, $37.4 \%$ vs. $30.4 \%, 34.2 \% / 27.3 \%$ vs. $27.6 \% / 14.2 \%$ and $25.0 \%$ vs. $20.1 \%$, respectively $(p<0.01)$. In summary, there is high prevalence of metabolic syndrome and its components in Chinese breast cancer women, and metabolic syndrome is closely related with breast cancer. Therefore, screening and prevention strategy of metabolic syndrome should be carried out in the management of breast cancer.
\end{abstract}

Key words: Breast cancer; metabolic syndrome; dyslipidemia; hypertension; hyperglycemia.

\section{Introduction}

Studies have shown that breast cancer is the most common cancer among females worldwide, which has seriously impacted the female health [1]. Although there are varieties of risk factors, such as age, genetic factors, menstrual status, reproductive and lifestyles, already known for breast cancer development, however oncologists have not paid appropriate attention to certain metabolic factors which may have major role in breast cancer development $[2,3]$.

Metabolic syndrome presents with a cluster of risk factors, including dyslipidemia, raised fasting 
blood glucose, raised waist circumference and raised blood pressure, for cardiovascular disease and type 2 diabetes mellitus [4]. As the economy has developed and lifestyle modifications have arisen as a result, the prevalence of metabolic syndrome has risen worldwide and it has now become a public health concern [5].

As recent studies [6-10] reported, metabolic syndrome is closely associated with the breast cancer development. A meta-analysis by Bhandari et al. [11] reported that metabolic syndrome can increase the risk of breast cancer in adult females, another meta-analysis by Esposito et al. [12] suggested that metabolic syndrome is associated with a moderately increased risk of postmenopausal breast cancer. In addition, metabolic syndrome is associated with increased risk of second breast cancer events and breast cancer specific mortality of early stage breast cancer during median follow-up of 6.3 years [7]. However, most original studies were conducted on Western populations, Asian population studies were rarely conducted. Besides, little is known about the prevalence of metabolic syndrome and its components among initially diagnosed breast cancer patients in Asia. Therefore, the purpose of present study is designed to investigate the prevalence and comparative analysis of metabolic syndrome and its components among breast cancer women and control population in China.

\section{Materials and Methods}

\section{Study design, participants and registration}

This is a case-control study which conducted in the Breast Cancer Center of Chongqing and Department of Physical Examination, the First Affiliated Hospital of Chongqing Medical University, Chongqing, which is situated in the southwest of China. There are approximately 31.4 million people who live in about $82,402.95 \mathrm{~km}^{2}$ area of Chongqing. This study was approved by the Administration Ethics Committee of the First Affiliated Hospital of Chongqing Medical University, and conducted in accordance to the Principles of Helsinki Declaration. This study was prospectively registered in Chinese Clinical Trial Registry (http://www.chictr.org.cn/, Registration number: ChiCTR-OOB-15007543).

In this study, we collected the data involving 3817 participants with reports of their metabolic components from Breast Cancer Center of Chongqing and Department of Physical Examination, the First Affiliated Hospital of Chongqing Medical University, Chongqing, China, from July 2015 to February 2017. The cases in group A were initially diagnosed breast cancer patients with pathological confirmation
( $n=605$ ), which was histopathologically diagnosed by the Clinical Pathology Diagnostic Center of Chongqing, Chongqing Medical University. The cases in group B were control population $(n=3212)$, in which all participants were from the same population in the similar period as group A, and ultrasound and/or mammography were used to screen for breast cancer in the Department of Physical Examination, and those positive of breast cancer were excluded (Figure 1). We performed a manual review of the participants' electronic records to collect the corresponding information. Eligible participants were females aged over 18 with reports of their metabolic components. Ineligible participants with following conditions were excluded: (1) Absence of pathological reports. (2) With a history of premenopausal hysterectomy. (3) With a history of other malignant tumors or coexistence of other serious medical conditions. (4) With incomplete data and history. (5) Those who can't stop taking medicines which have serious influence on blood sugar, blood pressure and blood lipid. Data collection, including age, sex, pathological diagnosis, medical history and metabolic indicators, was conducted by the researchers. In this study, we calculated the status of metabolic components and BMI, and stratified comparative analysis according to their age and BMI between breast cancer group and control population group.

\section{Measurement of variables}

Data of waist circumference, height, weight, blood pressure, serum lipid level and fasting blood glucose level were collected for analysis. Blood tests were performed by Department of Laboratory Medicine, the First Affiliated Hospital of Chongqing Medical University. Past medical history of participants were inquired and recorded in electronic medical record system.

\section{Definition of metabolic syndrome and body mass index (BMI)}

According to the definition of a Joint Scientific Statement[4], metabolic syndrome is defined as the presence of three or more of the following five risk factors: (1) Visceral obesity defined by waist circumference (population and country specific definitions, males $\geq 85 \mathrm{~cm}$ and females $\geq 80 \mathrm{~cm}$ for Chinese); (2) Triglycerides $\geq 150 \mathrm{mg} / \mathrm{dL}$; (3) Decreased high density lipoprotein cholesterol (HDL-C) levels (males < 40mg/dL, females < 50 $\mathrm{mg} / \mathrm{dL}$ ); (4) Blood pressure elevated (systolic $\geq 130$ $\mathrm{mmHg}$ and/or diastolic $\geq 85 \mathrm{mmHg}$ ); (5) Fasting blood glucose level $\geq 100 \mathrm{mg} / \mathrm{dL}$. 
Initial diagnosed breast cancer population was from the Breast

Cancer Center of Chongqing.

Eligible criteria:

(1) Female ages $\geq 18$ years

(2) Initial diagnosed breast cancer with pathological report.

(3) Without coexist of other serious medical history (e.g. other malignancies).

(4) With complete necessary data (e.g. metabolic syndrome indicators).

Cases were excluded if don't

meet the eligible criteria.

Medical records were screened from July 2015 to February 2017 in the electronic records system of the First Affiliated Hospital of Chongqing Medical University.

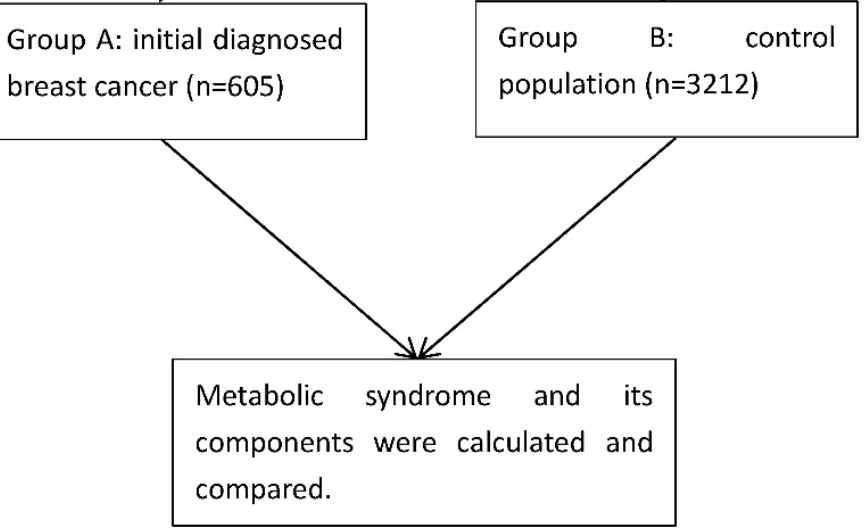

Control population was from the Department of Physical Examination $(n=4835)$.

Eligible criteria:

(1) Female ages $\geq 18$ years.

(2) Without serious medical history (e.g. cancer).

(3) With complete necessary data (e.g. metabolic syndrome indicators).

Cases were excluded if don't meet the eligible criteria.

Figure 1 Cases selection flow diagram

BMI is calculated as weight in kilograms divided by height in meters squared $\left(\mathrm{kg} / \mathrm{m}^{2}\right)$. BMI is classified with the following measures approved by the WHO expert consultation[13]: (1) Underweight: BMI < 18.5 $\mathrm{kg} / \mathrm{m} 2(<16.0 \mathrm{~kg} / \mathrm{m} 2$, severe underweight; 16.0-16.9 $\mathrm{kg} / \mathrm{m} 2$, moderate underweight; $17.0-18.49 \mathrm{~kg} / \mathrm{m} 2$, mild underweight); (2) Normal: BMI $18.5-24.9 \mathrm{~kg} / \mathrm{m} 2$; (3) Preobese: BMI 25.0-29.9 kg/m2; (4) Obesity: BMI $\geq$ $30.0 \mathrm{~kg} / \mathrm{m} 2$ (30.0-34.9 kg/m2, obese class I; 35.0-39.9 $\mathrm{kg} / \mathrm{m} 2$, obese class II; $\geq 40.0 \mathrm{~kg} / \mathrm{m} 2$, obese class III). The status of metabolic syndrome by the BMI stratification among breast cancer patients and control population was analyzed.

\section{Statistical analysis}

All statistics were calculated by Microsoft Office 2010 and Statistical Package for Social Science Program (SPSS, version 19, Chicago, IL). All p values were two-sided and $p<0.05$ was considered to be statistically significant for all analyses. Pearson
Chi-Square test and Continuity Correction Chi-Square test were mainly used to comparative analysis of the $p$ values for count variables of metabolic syndrome and its components among breast cancer patients and control population. Besides, we estimated odds ratio (OR) and 95\% confidence interval (CI) using univariate logistic regression analysis model to assess the metabolic syndrome among breast cancer patients and control population.

\section{Results}

\section{Characteristics of the study population}

A total of 3817 participants were eligible, of which 605 participants were initially female breast cancer patients (median age: 50.3 years), the other 3212 participants were control females (median age: 46.6 years) from our physical examination system within the same time frame. The average BMI of primary female breast cancer patients and control 
females group was $23.9 \mathrm{~kg} / \mathrm{m} 2$ and $22.5 \mathrm{~kg} / \mathrm{m} 2$. Originally, we extracted 4835 control females' physical examination data for preliminary screening, further we excluded those without intact metabolic syndrome indicators, BMI, medical history and basic information, finally 3212 control females remained for further analysis. The metabolic syndrome indicators, BMI, medical history and basic information of the 605 primary female breast cancer patients from the Breast Cancer Center of Chongqing record system were measured at the time of first hospitalized.

\section{The prevalence of metabolic syndrome}

The prevalence of metabolic syndrome in primarily diagnosed breast cancer patients $(32.6 \%)$ was statistically higher than that $(18.2 \%)$ of control population ( $\mathrm{p}<0.001$; OR: $2.173,95 \%$ CI: 1.793 to 2.633 ) (Table 1).

With age stratification, the prevalence of metabolic syndrome in breast cancer group aged below 60 years $(24.9 \%)$ and equal/above 60 years $(58.3 \%)$ were also statistically higher than those $(13.0 \%$ \& $37.9 \%)$ in control population, respectively ( $\mathrm{p}<0.001$; OR: 2.216, 95\%CI: 1.744 to 2.816$)$ and ( $p<0.001$; OR: 2.291, 95\%CI: 1.580 to 3.322). With further stratification in the group aged below 60 years, the difference was statistically significant, except for the subgroup between 30 to 39 years old (Table 1).

The prevalence of preobese or obesity (BMI $\geq 25)$ in breast cancer group (31.7\%) was obviously higher than that $(19.4 \%)$ in control population. With BMI stratification, the prevalence of metabolic syndrome in subgroup underweight $(\mathrm{BMI}<18.5)$, normal $(18.5 \leq$ BMI $<25)$, preobese $(25 \leq \mathrm{BMI}<30)$ and obesity $(\mathrm{BMI} \geq 30)$ was $0 \%, 22.1 \%, 57.6 \%$ and $61.8 \%$ in breast cancer group, respectively, while the corresponding prevalence in control population were $1.9 \%, 10.1 \%$, $52.7 \%$ and $72.4 \%$, respectively. Statistically difference between breast cancer and control population was observed only in the normal BMI $(18.5 \leq \mathrm{BMI}<25)$ subgroup ( $\mathrm{p}<0.001$; OR: $2.525,95 \% \mathrm{CI}: 1.917$ to 3.326 ). Moreover, a trend was observed that with higher the BMI, subjects were more likely to have metabolic syndrome regardless in both breast cancer patients and control population (Table 1).

\section{Comparative analysis of the prevalence of metabolic syndrome between normal BMI and abnormal BMI population}

Breast cancer patients with preobese (BMI 25.0-29.9) or obesity (BMI $\geq 30.0$ ) were more likely to have metabolic syndrome $(58.3 \%)$ compared to those with normal BMI $(18.5 \leq \mathrm{BMI}<25)(22.1 \%)(\mathrm{p}<0.001$; OR: $4.925,95 \% \mathrm{CI}: 3.386$ to 7.163$)$, corresponding analysis results in control population were $54.5 \%$ and $10.1 \%$
( $\mathrm{p}<0.001$; OR: 10.635, 95\% CI: 8.651 to 13.074) (Table 2). After stratification analyses by age $<60$ and $\geq 60$, the difference was remain significant. It suggests that preobese (BMI 25.0-29.9) or obesity (BMI $\geq 30.0$ ) is a risk factor for metabolic syndrome whether in breast cancer patients or control population.

However, when compared the prevalence of metabolic syndrome in the normal BMI group (18.5 $\leq$ $\mathrm{BMI}<25) \quad(22.1 \%)$ with the underweight group $(\mathrm{BMI}<18.5)(0 \%)$ in breast cancer patients, the difference was statistically significant $(p=0.009)$, corresponding results in control population were $10.1 \%$ and $1.9 \%$ ( $\mathrm{p}<0.001$; OR: 5.966, 95\% CI: 2.199 to 16.188) (Table 2). However, after stratification analyse by age $<60$ and $\geq 60$, the difference was only significant in control population subgroup age $<60$ $(p=0.001)$. Therefore, it is suggested that the higher the BMI, the more risk to have metabolic syndrome in both breast cancer group as well as control population. It is noted that due to the small sample size in the underweight group, the prevalence of metabolic syndrome in the underweight breast cancer group was $0 \%$, which requires further investigation.

\section{The status of individual metabolic syndrome components}

With regards to individual metabolic syndrome components, breast cancer patients were more likely to have broader waist circumference, lower HDL-C level, higher systolic and/or diastolic blood pressure and higher fasting blood glucose level compared to the control population, corresponding prevalence were $76.0 \%$ vs. $29.6 \%, 37.4 \%$ vs. $30.4 \%, 34.2 \% / 27.3 \%$ vs. $27.6 \% / 14.2 \%$ and $25.0 \%$ vs. $20.1 \%$, respectively. Interestingly, the raised triglyceride level was lower in breast cancer patients $(14.5 \%)$ compared with control population $(18.3 \%)$. The difference of all the individual components between the two groups were found to be statistically significant overall $(\mathrm{p}<0.05)$. After stratification analyses by age $<60$ and $\geq 60$, the difference was significant in most of the subgroups $(\mathrm{p}<0.05)$, except the triglyceride and fasting blood glucose in subgroup age $<60$ ( $p>0.05)$, the HDL-C and systolic blood pressure in subgroup age $\geq 60(p>0.05)$ (Table 3).

When came to the number of metabolic syndrome components in individual subjects, metabolic syndrome components were totally absent in $12.2 \%$ and $38.8 \%$ subjects in breast cancer and control population group, respectively. Meanwhile, a single metabolic syndrome component was observed in $24.8 \%$ breast cancer patients and $26.5 \%$ control population, besides, two of the components were found in $30.4 \%$ breast cancer patients and 16.5\% control population. Cases with three or above 
components were defined as metabolic syndrome, which presented in $32.6 \%$ breast cancer patients and $18.2 \%$ control population respectively. The number of cases with two or more components was higher in breast cancer group compared to control population group, the difference was statistically significant overall and stratification by age $<60$ and $\geq 60(p<0.05)$ (Table 4).

\section{Discussion}

Recently, several studies showed that metabolic syndrome has increased the risk of breast cancer occurrence, recurrence and breast cancer specific mortality $[8,10,14,15]$. A meta-analysis, including a total number of 97,277 adult females from nine independent cohorts, found metabolic syndrome significantly increased the risk of breast cancer by $47 \%$ [11]. Meanwhile, the metabolic syndrome is prevalent worldwide, thus the influence of metabolic syndrome should not be ignored [16]. Since the definition of metabolic syndrome is population specific and the regional economic development different, the prevalence of metabolic syndrome is also population specific $[4,17]$. A national cross-sectional survey of
China indicated that the prevalence of metabolic syndrome and overweight was $17.8 \%$ and $31.1 \%$ in women, which has become a significant public health burden [18]. However, we know little about the prevalence of metabolic syndrome and overweight in breast cancer in China.

Our study shows a higher prevalence of metabolic syndrome in breast cancer patients $(32.6 \%)$ compared to control population (18.2\%), besides there is an even higher prevalence of metabolic syndrome in breast cancer patients of equal/above 60 years (58.3\%). Although we couldn't separate the breast cancer patients into premenopausal and postmenopausal, the subgroup patients of equal/above 60 years were considered as postmenopausal. As previously reported [19], the prevalence of metabolic syndrome in postmenopausal breast cancer patients was $53.7 \%$, which is in accordance to our study. However, the previous study only involved 67 postmenopausal breast cancer patients [19], thus our study seems to provide a larger sample of participants and obtain more powerful evidences.

Table 1. Metabolic syndrome among control population and breast cancer patients

\begin{tabular}{|c|c|c|c|c|c|c|c|c|}
\hline \multirow{2}{*}{\multicolumn{2}{|c|}{ Variable }} & \multicolumn{3}{|c|}{ Breast cancer patients } & \multicolumn{3}{|c|}{ Control population } & \multirow[t]{2}{*}{ OR(95\%CI);p value } \\
\hline & & MS & Non-MS & total & MS & Non-MS & total & \\
\hline Num & & $197(32.6 \%)$ & $408(67.4 \%)$ & 605 & $584(18.2 \%)$ & $2628(81.8 \%)$ & 3212 & $2.173(1.793,2.633) ; \mathrm{p}<0.001$ \\
\hline Age, & mean $\pm S D$ ) & $55.8 \pm 9.9$ & $47.6 \pm 10.6$ & $50.3 \pm 11.1$ & $56 \pm 13.1$ & $44.4 \pm 13.9$ & $46.6 \pm 14.5$ & - \\
\hline \multicolumn{9}{|c|}{ Age stratification, years } \\
\hline$<60$ & & $116(24.9 \%)$ & $350(75.1 \%)$ & 466 & $331(13.0 \%)$ & $2213(87.0 \%)$ & 2544 & $2.216(1.744,2.816) ; \mathrm{p}<0.001$ \\
\hline & $18-29$ & $3(21.4 \%)$ & $11(78.6 \%)$ & 14 & $14(3.2 \%)$ & $429(96.8 \%)$ & 443 & $\mathrm{p}=0.005^{*}$ \\
\hline & $30-39$ & $4(5.3 \%)$ & $71(94.7 \%)$ & 75 & $42(6.5 \%)$ & $605(93.5 \%)$ & 647 & $\mathrm{p}=0.889^{*}$ \\
\hline & $40-49$ & $44(20.4 \%)$ & $172(79.6 \%)$ & 216 & $117(14.3 \%)$ & $699(85.7 \%)$ & 816 & $\mathrm{p}=0.030$ \\
\hline & $50-59$ & $65(40.4 \%)$ & $96(59.6 \%)$ & 161 & $158(24.8 \%)$ & $480(75.2 \%)$ & 638 & $2.057(1.431,2.956) ; \mathrm{p}<0.001$ \\
\hline$\geq 60$ & & $81(58.3 \%)$ & $58(41.7 \%)$ & 139 & $253(37.9 \%)$ & $415(62.1 \%)$ & 668 & $2.291(1.580,3.322) ; \mathrm{p}<0.001$ \\
\hline \multicolumn{9}{|c|}{ Body mass index (BMI) kg/m2 } \\
\hline & Mean \pm SD & $25.7 \pm 3.4$ & $23.1 \pm 4.1$ & $23.9 \pm 5.5$ & $25.6 \pm 3.1$ & $21.8 \pm 2.6$ & $22.5 \pm 3.1$ & - \\
\hline & Underweight $(\mathrm{BMI}<18.5)$ & $0(0 \%)$ & $29(100 \%)$ & 29 & $4(1.9 \%)$ & $212(98.1 \%)$ & 216 & $\mathrm{p}=1.000^{*}$ \\
\hline & Normal $(18.5 \leq \mathrm{BMI}<25)$ & $85(22.1 \%)$ & $299(77.9 \%)$ & 384 & $240(10.1 \%)$ & $2132(89.9 \%)$ & 2372 & $2.525(1.917,3.326) ; \mathrm{p}<0.001$ \\
\hline & Preobese $(25 \leq \mathrm{BMI}<30)$ & $91(57.6 \%)$ & $67(42.4 \%)$ & 158 & $298(52.7 \%)$ & $268(47.3 \%)$ & 566 & $\mathrm{p}=0.270$ \\
\hline & Obesity (BMI $\geq 30)$ & $21(61.8 \%)$ & $13(38.2 \%)$ & 34 & $42(72.4 \%)$ & $16(27.6 \%)$ & 566 & $\mathrm{p}=0.289$ \\
\hline
\end{tabular}

${ }^{*}$ Continuity Correction Chi-Square Test.

Table 2. The influence of body mass index (BMI) on the metabolic syndrome among control population and breast cancer patients

\begin{tabular}{|c|c|c|c|c|c|c|c|c|c|}
\hline \multirow[t]{2}{*}{ Variable } & \multirow{2}{*}{$\begin{array}{l}\text { Stratify } \\
\text { by age } \\
\text { (years) }\end{array}$} & \multicolumn{4}{|c|}{ Breast cancer patients $(n=605)$} & \multicolumn{4}{|c|}{ Control population $(\mathrm{n}=3212)$} \\
\hline & & MS & Non-MS & $\begin{array}{l}\mathrm{p} \text { and OR } \\
(95 \% \mathrm{CI})^{*}\end{array}$ & $\begin{array}{l}\mathrm{p} \text { and OR } \\
(95 \% \mathrm{CI})^{* *}\end{array}$ & MS & Non-MS & $\mathrm{p}$ and $\mathrm{OR}(95 \% \mathrm{CI})^{*}$ & $\begin{array}{l}\mathrm{p} \text { and OR } \\
(95 \% \mathrm{CI})^{* *}\end{array}$ \\
\hline \multirow{3}{*}{$\begin{array}{l}\text { Underweight } \\
(\mathrm{BMI}<18.5), \mathrm{n}(\%)\end{array}$} & total & $0(0 \%)$ & $29(100 \%)$ & \multirow{9}{*}{$\begin{array}{l}\text { total:p=0. } \\
009 \#,-; \\
\text { subgroup } \\
<60: p=0.0 \\
74 \#,-; \\
\text { subgroup } \\
\geq 60: p=0.0 \\
54 \#,-;\end{array}$} & \multirow{3}{*}{$\begin{array}{l}\text { total: } \mathrm{p}<0.001 \\
4.925(3.386-7.163) \\
\text { subgroup }<60: \mathrm{p}<0.0\end{array}$} & $4(1.9 \%)$ & $212(98.1 \%)$ & \multirow{3}{*}{$\begin{array}{l}\text { total:p<0.001\#, } \\
5.966(2.199-16.188) ; \\
\text { subgroup }<60: p=0.0\end{array}$} & \multirow{3}{*}{$\begin{array}{l}\text { total:p<0.001, } \\
10.635(8.651-13.074 \\
)\end{array}$} \\
\hline & $<60$ & $0(0 \%)$ & $23(79.3 \%)$ & & & $1(0.5 \%)$ & $191(88.4 \%)$ & & \\
\hline & $\geq 60$ & $0(0 \%)$ & $6(20.7 \%)$ & & & $3(1.4 \%)$ & $21(9.7 \%)$ & & \\
\hline \multirow{3}{*}{$\begin{array}{l}\text { Normal } \\
(18.5 \leq \mathrm{BMI}<25), \mathrm{n}(\%)\end{array}$} & total & $85(22.1 \%)$ & $299(77.9 \%)$ & & \multirow{3}{*}{$\begin{array}{l}01 \\
5.448(3.442-8.622) \\
\text { subgroup } \geq 60: p=0.0 \\
08,\end{array}$} & $240(10.1 \%)$ & $2132(89.9 \%)$ & \multirow{6}{*}{$\begin{array}{l}01 \#, \\
13.340(1.854-95.982 \\
) ; \\
\text { subgroup } \geq 60: p=0.2 \\
22 \# \text {, } \\
2.433(0.712-8.310) ;\end{array}$} & subgroup $<60$ : $p<0.0$ \\
\hline & $<60$ & $51(13.3 \%)$ & $265(69.0 \%)$ & & & $126(5.3 \%)$ & $1804(76.1 \%)$ & & $\begin{array}{l}01, \\
13,526(10,400-17.59\end{array}$ \\
\hline & $\geq 60$ & $34(8.8 \%)$ & $34(8.9 \%)$ & & & $114(4.8 \%)$ & $328(13.8 \%)$ & & \\
\hline \multirow{3}{*}{$\begin{array}{l}\text { Preobese/Obesity } \\
(\mathrm{BMI} \geq 25), \mathrm{n}(\%)\end{array}$} & total & $112(58.3 \%)$ & $80(41.7 \%)$ & & \multirow[t]{3}{*}{$2.611(1.269-5.374)$} & $340(54.5 \%)$ & $284(45.5 \%)$ & & subgroup $\geq 60$ :p $<0.0$ \\
\hline & $<60$ & $65(33.8 \%)$ & $62(32.3 \%)$ & & & $205(32.9 \%)$ & $217(34.8 \%)$ & & \\
\hline & $\geq 60$ & $47(24.5 \%)$ & $18(9.4 \%)$ & & & $135(21.6 \%)$ & $67(10.7 \%)$ & & 5.797(4.036-8.328); \\
\hline
\end{tabular}

\# Continuity Correction Chi-Square Test. * Comparison of the normal BMI group and the underweight group. ${ }^{* *}$ Comparison of the preobese/obesity group and the normal BMI group. 
Table 3. The status of individual metabolic syndrome components among control population and breast cancer patients

\begin{tabular}{|c|c|c|c|c|}
\hline Variable & $\begin{array}{l}\text { Stratify } \\
\text { by age } \\
\text { (years) }\end{array}$ & $\begin{array}{l}\text { Breast } \\
\text { cancer } \\
\text { patients } \\
(\mathrm{n}=605)(\%)\end{array}$ & $\begin{array}{l}\text { Control } \\
\text { population } \\
(n=3212)(\%)\end{array}$ & $\mathrm{p}$ value \\
\hline $\begin{array}{l}\text { Age, years } \\
\text { (mean } \pm S D)\end{array}$ & - & $50.3 \pm 11.1$ & $46.6 \pm 14.5$ & - \\
\hline \multicolumn{5}{|l|}{$\begin{array}{l}\text { Waist } \\
\text { circumference }\end{array}$} \\
\hline \multirow[t]{3}{*}{$<80 \mathrm{~cm}$} & total & $145(24.0 \%)$ & $2261(70.4 \%)$ & total: $\mathrm{p}<0.001$ \\
\hline & $<60$ & $130(21.5 \%)$ & $1917(59.7 \%)$ & subgroup $<60$ :p $<0.001 ;$ \\
\hline & $\geq 60$ & $15(2.5 \%)$ & $344(10.7 \%)$ & subgroup $\geq 60$ : $p<0.001 ;$ \\
\hline \multirow[t]{3}{*}{$\geq 80 \mathrm{~cm}$} & total & $460(76.0 \%)$ & $951(29.6 \%)$ & \\
\hline & $<60$ & $336(55.5 \%)$ & $627(19.5 \%)$ & \\
\hline & $\geq 60$ & $124(20.5 \%)$ & $324(10.1 \%)$ & \\
\hline \multicolumn{5}{|l|}{ Triglyceride } \\
\hline \multirow[t]{3}{*}{$<150 \mathrm{mg} / \mathrm{dL}$} & total & $517(85.5 \%)$ & $2624(81.7 \%)$ & total: $\mathrm{p}=0.026$ \\
\hline & $<60$ & $410(67.8 \%)$ & $2174(67.7 \%)$ & subgroup $<60$ : $p=0.150 ;$ \\
\hline & $\geq 60$ & $107(17.7 \%)$ & $450(14.0 \%)$ & subgroup $\geq 60: p=0.026 ;$ \\
\hline \multirow[t]{3}{*}{$\geq 150 \mathrm{mg} / \mathrm{dL}$} & total & $88(14.5 \%)$ & $588(18.3 \%)$ & \\
\hline & $<60$ & $56(9.2 \%)$ & $370(11.5 \%)$ & \\
\hline & $\geq 60$ & $32(5.3 \%)$ & $218(6.8 \%)$ & \\
\hline \multicolumn{5}{|c|}{$\begin{array}{l}\text { High-density } \\
\text { lipoprotein (HDL) }\end{array}$} \\
\hline \multirow[t]{3}{*}{$<50 \mathrm{mg} / \mathrm{dL}$} & total & $226(37.4 \%)$ & $977(30.4 \%)$ & total:p=0.001; \\
\hline & $<60$ & $176(29.1 \%)$ & $743(23.1 \%)$ & subgroup $<60$ :p $<0.001 ;$ \\
\hline & $\geq 60$ & $50(8.3 \%)$ & $234(7.3 \%)$ & subgroup $\geq 60: p=0.833 ;$ \\
\hline \multirow[t]{3}{*}{$\geq 50 \mathrm{mg} / \mathrm{dL}$} & total & $379(62.6 \%)$ & $2235(69.6 \%)$ & \\
\hline & $<60$ & $290(47.9 \%)$ & $1801(56.1 \%)$ & \\
\hline & $\geq 60$ & $89(14.7 \%)$ & $434(13.5 \%)$ & \\
\hline \multicolumn{5}{|l|}{$\begin{array}{l}\text { Systolic blood } \\
\text { pressure }\end{array}$} \\
\hline \multirow[t]{3}{*}{$<130 \mathrm{mmHg}$} & total & $398(65.8 \%)$ & $2327(72.4 \%)$ & total: $\mathrm{p}=0.001$ \\
\hline & $<60$ & $342(56.5 \%)$ & $2089(65.0 \%)$ & subgroup $<60$ :p $<0.001 ;$ \\
\hline & $\geq 60$ & $56(9.3 \%)$ & $238(7.4 \%)$ & subgroup $\geq 60: p=0.299 ;$ \\
\hline \multirow[t]{3}{*}{$\geq 130 \mathrm{mmHg}$} & total & $207(34.2 \%)$ & $885(27.6 \%)$ & \\
\hline & $<60$ & $124(20.5 \%)$ & $455(14.2 \%)$ & \\
\hline & $\geq 60$ & $83(13.7 \%)$ & $430(13.4 \%)$ & \\
\hline \multicolumn{5}{|l|}{$\begin{array}{l}\text { Diastolic blood } \\
\text { pressure }\end{array}$} \\
\hline \multirow[t]{3}{*}{$<85 \mathrm{mmHg}$} & total & $440(72.7 \%)$ & $2755(85.8 \%)$ & total:p<0.001; \\
\hline & $<60$ & $352(58.2 \%)$ & $2248(70.0 \%)$ & subgroup $<60$ : $p<0.001 ;$ \\
\hline & $\geq 60$ & $88(14.5 \%)$ & $507(15.8 \%)$ & subgroup $\geq 60: p=0.002 ;$ \\
\hline \multirow[t]{3}{*}{$\geq 85 \mathrm{mmHg}$} & total & $165(27.3 \%)$ & $457(14.2 \%)$ & \\
\hline & $<60$ & $114(18.9 \%)$ & $296(9.2 \%)$ & \\
\hline & $\geq 60$ & $51(8.4 \%)$ & $161(5.0 \%)$ & \\
\hline \multicolumn{5}{|l|}{$\begin{array}{l}\text { Fasting blood } \\
\text { glucose (FBG) }\end{array}$} \\
\hline \multirow[t]{3}{*}{$<100 \mathrm{mg} / \mathrm{dL}$} & total & $454(75.0 \%)$ & $2566(79.9 \%)$ & total: $\mathrm{p}=0.007$ \\
\hline & $<60$ & $387(64.0 \%)$ & $2173(67.7 \%)$ & subgroup $<60: p=0.187 ;$ \\
\hline & $\geq 60$ & $67(11.0 \%)$ & $393(12.2 \%)$ & subgroup $\geq 60: p=0.021 ;$ \\
\hline \multirow[t]{3}{*}{$\geq 100 \mathrm{mg} / \mathrm{dL}$} & total & $151(25.0 \%)$ & $646(20.1 \%)$ & \\
\hline & $<60$ & $79(13.1 \%)$ & $371(11.5 \%)$ & \\
\hline & $\geq 60$ & $72(11.9 \%)$ & $275(8.6 \%)$ & \\
\hline
\end{tabular}

In our study, we observed the prevalence of preobese or obesity $(\mathrm{BMI} \geq 25)$ was $31.7 \%$ in breast cancer and $19.4 \%$ in control population. According to the BMI stratification analysis, a trend was observed that when the BMI is increasing, the risk of metabolic syndrome increased regardless in both breast cancer patients and control population. Various studies have shown that metabolic risk factors were positively associated with BMI, the higher the BMI the more metabolic risk factors acquired [20]. BMI is an indicator for obesity, but not exactly of abdominal obesity [21].

Table 4. Number of metabolic syndrome components among control population and breast cancer patients

\begin{tabular}{lllll}
\hline $\begin{array}{l}\text { Number of } \\
\text { components }\end{array}$ & $\begin{array}{l}\text { Stratify by } \\
\text { age (years) }\end{array}$ & $\begin{array}{l}\text { Breast cancer } \\
\text { patients } \\
(\mathrm{n}=605)(\%)\end{array}$ & $\begin{array}{l}\text { Control } \\
\text { population } \\
(\mathrm{n}=3212)(\%)\end{array}$ & p value \\
\hline $\mathbf{0}$ & total & $74(12.2 \%)$ & $1246(38.8 \%)$ & total: $\mathrm{p}<0.001 ;$ \\
& $<60$ & $71(11.7 \%)$ & $1175(36.6 \%)$ & $\begin{array}{l}\text { subgroup }<60: \\
\mathrm{p}<0.001 ;\end{array}$ \\
$\mathbf{1}$ & $\geq 60$ & $3(0.5 \%)$ & $71(2.2 \%)$ & $\begin{array}{l}\text { subgroup } \geq 60: \\
\end{array}$ \\
& total & $150(24.8 \%)$ & $851(26.5 \%)$ & $\mathrm{p}<0.001 ;$ \\
$\mathbf{2}$ & $<60$ & $133(22.0 \%)$ & $699(21.8 \%)$ & \\
& $\geq 60$ & $17(2.8 \%)$ & $152(4.7 \%)$ & \\
& total & $184(30.4 \%)$ & $531(16.5 \%)$ & \\
$3 \sim 5$ & $<60$ & $146(24.1 \%)$ & $339(10.5 \%)$ & \\
& $\geq 60$ & $38(6.3 \%)$ & $192(6.0 \%)$ & \\
& total & $197(32.6 \%)$ & $584(18.2 \%)$ & \\
& $<60$ & $116(19.2 \%)$ & $331(10.3 \%)$ & \\
\hline
\end{tabular}

The waist circumference, as a criterion of metabolic syndrome diagnosis, is an important indicator for abdominal obesity, and the definition of waist circumference measure is population specific according to different regions [4]. In our study, the prevalence of excessive waist circumference was $76.0 \%$ in breast cancer and $29.6 \%$ in control population, which suggests a high prevalence of abdominal obesity in breast cancer. As $\mathrm{He}$ et al. reported, abdominal obesity was associated with a significantly higher metabolic syndrome burden [22]. Abdominal obesity is a marker of dysfunctional adipose tissue which could contribute to the insulin resistant and inflammatory reaction, and further activate the signaling pathway of cancer development [23].

We observed the prevalence of raised triglyceride was $14.5 \%$ in breast cancer and $18.3 \%$ in control population. It is interesting that the prevalence of raised triglyceride was lower in breast cancer patients compared to control population. We speculate that the hypermetabolism of cancer cells might use the serum lipid as its fuel, so the level of the triglyceride was lower in breast cancer patients [24]. As a meta-analysis by Ma et al reported, the serum triglycerides was not associated with the risk of breast cancer [25]. Besides, the prevalence of low HDL-C level was higher in breast cancer $(37.4 \%)$ compared to control population (30.4\%). Previous studies [26-28] have indicated that low levels of HDL-C were correlated with negative prognosis in various types of cancer, although the mechanism remains unclear.

In our study, the prevalence of raised systolic or diastolic blood pressure is higher in breast cancer 
patients compared to control population. Han et al. [29] suggested that hypertension was associate with increased risk of breast cancer, specifically for postmenopausal women. Besides, hypertension, as a cardiovascular risk factor, would undoubtedly negative affect the prognosis of breast cancer [30].

Additionally, the prevalence of raised fasting blood glucose is higher in breast cancer compared to control population. Previous studies suggested that prediabetes and diabetes, as the results of peripheral insulin resistance and dysfunctional insulin secretion, were risk factors of breast cancer in women [31, 32]. Insulin resistance is not only the reason for diabetes, but also a potentially key role of metabolic syndrome [33]. Therefore, correcting insulin resistance plays an important role in preventing both metabolic syndrome and breast cancer.

Metabolic syndrome, defined as a cluster of metabolic risk factors occur together in human body, is identified as a risk factor for breast cancer [8, 10-12]. Our study shows that the prevalence of metabolic syndrome was $32.6 \%$ in breast cancer and $18.2 \%$ in control population. Meanwhile, more metabolic syndrome components were present in breast cancer compared to control population. Although more metabolic syndrome and its components were present in breast cancer patients, many control population had metabolic syndrome and its components, especially those who were obese or preobese, they are of great risk of future cardiovascular disease. There are several reasons explaining the high prevalence of metabolic syndrome and its components. Above all, people have less physical activity due to the modern life pace has changed. Besides, dietary intake has changed a lot because of the economy has developed, more fat and calorie are taken, thus more people become overweight. Thus, it is suggested that the lifestyle behaviors modification would result in a decrease in metabolic syndrome and its components [34-36], however, a lifestyle with low-fat, low-calorie, appropriate intensity exercise and weight control would be good for decreasing in metabolic syndrome and its components [34].

To our knowledge, this is the largest sample study of metabolic syndrome among breast cancer patients and control population in China. Our finding provides the prevalence of metabolic syndrome and its components in breast cancer and control population, and suggests that metabolic syndrome may be a risk factor for breast cancer development. We would like to state several limitations of our study. The participants recruited here were subject to selection bias as there were all female and not selected at random from the whole population. Furthermore, there were several cofactors that may influence the results that can't be evaluated due to the limitation of data, such as prescribed medication using, cigarette smoking and alcohol using. Additionally, due to the fact that it would take a long duration of time for the biological mechanism of metabolic syndrome to affect the development of breast cancer, prospective study should be conducted to identify the relationship between metabolic syndrome and breast cancer in further research. Finally, we haven't obtained follow-up data about prognosis due to limited time period. In further study, we would like to research the influence of metabolic syndrome in the treatment and prognosis of breast cancer.

\section{Conclusions}

In conclusion, our study shows a high prevalence of metabolic syndrome in Chinese breast cancer patients, and BMI is closely associated with metabolic syndrome. Our study results indicate that metabolic syndrome and its components are present to a greater degree in Chinese breast cancer women compared to control population, metabolic syndrome is closely related with breast cancer regardless of the menopausal status. Therefore, we believe that our results support the screening of metabolic syndrome in breast cancer. Besides, we suggest that appropriate prevention and active treatment of metabolic syndrome and its components should be considered in the management of breast cancer patients.

\section{Acknowledgments}

We would like to thank all participants, the Breast Cancer Center and Physical Examination Center of Chongqing for their contributions that have made this study possible.

\section{Contributors}

YTW, XL, BA, ZX, LR, LQK: Conception (LQK), design, data collection, data analysis, interpretation of results, manuscript writing (YTW) and editing (LQK), approval of final version. CXZ, HW, YLS, HRC, HL, HYL, KNW: Data collection, interpretation of results, approval of final version. LQK is the guarantor of this work and had full access to all the data in the study and takes responsibility for the integrity of the data and the accuracy of the data analysis.

\section{Funding}

This study was funded by Graduate Student's Science Innovation Project of Chongqing (CYS16124) and National Natural Science Foundation of China (NSFC) (81372851).

\section{Ethical Approval}

This study was approved by the Administration 
Ethics Committee and conducted in accordance with the Principles of Helsinki Declaration.

\section{Competing Interests}

The authors have declared that no competing interest exists.

\section{References}

1. Siegel RL, Miller KD, Jemal A. Cancer statistics, 2016. CA Cancer J Clin. 2016; 66: 7-30.

2. Wiseman M. The second World Cancer Research Fund/American Institute for Cancer Research expert report. Food, nutrition, physical activity, and the prevention of cancer: a global perspective. The Proceedings of the Nutrition Society. 2008; 67: 253-6.

3. Eden JA. Menopausal status, adipose tissue, and breast cancer risk: impact of estrogen replacement therapy. Hormone molecular biology and clinical investigation. 2013; 14: 57-63.

4. Alberti KG, Eckel RH, Grundy SM, Zimmet PZ, Cleeman JI, Donato KA, et al. Harmonizing the metabolic syndrome: a joint interim statement of the International Diabetes Federation Task Force on Epidemiology and Prevention; National Heart, Lung, and Blood Institute; American Heart Association; World Heart Federation; International Atherosclerosis Society; and International Association for the Study of Obesity. Circulation. 2009; 120: 1640-5.

5. Aguilar M, Bhuket T, Torres S, Liu B, Wong RJ. Prevalence of the metabolic syndrome in the United States, 2003-2012. Jama. 2015; 313: 1973-4.

6. Hauner D, Hauner H. Metabolic syndrome and breast cancer: is there a link? Breast Care (Basel). 2014; 9: 277-81.

7. Calip GS, Malone KE, Gralow JR, Stergachis A, Hubbard RA, Boudreau DM. Metabolic syndrome and outcomes following early-stage breast cancer. Breast Cancer Res Treat. 2014; 148: 363-77.

8. Agnoli C, Grioni S, Sieri S, Sacerdote C, Ricceri F, Tumino R, et al. Metabolic Syndrome and Breast Cancer Risk: A Case-Cohort Study Nested in a Multicentre Italian Cohort. Plos One. 2015; 10: e0128891.

9. Sheean P, Liang H, Schiffer L, Arroyo C, Stolley M. Examining the prevalence of metabolic syndrome among overweight/obese African-American breast cancer survivors vs. matched non-cancer controls. Journal of Cancer Survivorship. 2016; 11: 102-10.

10. Lee JA, Yoo JE, Park HS. Metabolic syndrome and incidence of breast cancer in middle-aged Korean women: a nationwide cohort study. Breast Cancer Res Treat. 2017; 162: 389-93.

11. Bhandari R, Kelley GA, Hartley TA, Rockett IR. Metabolic syndrome is associated with increased breast cancer risk: a systematic review with meta-analysis. Int J Breast Cancer. 2014; 2014: 189384

12. Esposito K, Chiodini P, Capuano A, Bellastella G, Maiorino MI, Rafaniello C, et al. Metabolic syndrome and postmenopausal breast cancer: systematic review and meta-analysis. Menopause. 2013; 20: 1301-9.

13. Consultation WE. Appropriate body-mass index for Asian populations and its implications for policy and intervention strategies. Lancet (London, England). 2004; 363: 157-63.

14. Pasanisi P, Berrino F, De Petris M, Venturelli E, Mastroianni A, Panico S. Metabolic syndrome as a prognostic factor for breast cancer recurrences. Int J Cancer. 2006; 119: 236-8

15. Esposito K, Chiodini P, Colao A, Lenzi A, Giugliano D. Metabolic syndrome and risk of cancer: a systematic review and meta-analysis. Diabetes care. 2012; 35: 2402-11.

16. Cameron AJ, Shaw JE, Zimmet PZ. The metabolic syndrome: prevalence in worldwide populations. Endocrinol Metab Clin North Am. 2004; 33: 351-75, table of contents.

17. M A, T B, S T, B L, RJ W. Prevalence of the Metabolic Syndrome in the United States, 2003-2012. Jama. 2015; 313: 1973-4.

18. Gu D, Reynolds K, Wu X, Chen J, Duan X, Reynolds RF, et al. Prevalence of the metabolic syndrome and overweight among adults in China. The Lancet. 2005; 365: 1398-405

19. López DML, Lara MC, Almagro DM, Herrera AM, Cortés RM, Cardoso RT. Metabolic syndrome and prognostic factors in postmenopausal breast cancer patients. Maturitas. 2015; 81: 189.

20. Laurson KR, Welk GJ, Eisenmann JC. Diagnostic performance of BMI percentiles to identify adolescents with metabolic syndrome. Pediatrics. 2014; 133: e330-8.

21. Silva V, Stanton KR, Grande AJ. Harmonizing the diagnosis of metabolic syndrome--focusing on abdominal obesity. Metab Syndr Relat Disord. 2013; 11: $102-8$.

22. He F, Rodriguez-Colon S, Fernandez-Mendoza J, Vgontzas AN, Bixler EO, Berg A, et al. Abdominal obesity and metabolic syndrome burden in adolescents--Penn State Children Cohort study. J Clin Densitom. 2015; 18: 30-6.

23. Despres JP, Lemieux I. Abdominal obesity and metabolic syndrome. Nature. 2006; 444: 881-7.
24. Nelson ER, Wardell SE, Jasper JS, Park S, Suchindran S, Howe MK, et al. 27-Hydroxycholesterol links hypercholesterolemia and breast cancer pathophysiology. Science. 2013; 342: 1094-8.

25. Ma HQ, Cui LH, Li CC, Yu Z, Piao JM. Effects of Serum Triglycerides on Prostate Cancer and Breast Cancer Risk: A Meta-Analysis of Prospective Studies. Nutr Cancer. 2016; 68: 1073-82.

26. Dai D, Chen B, Wang B, Tang H, Li X, Zhao Z, et al. Pretreatment TG/HDL-C Ratio Is Superior to Triacylglycerol Level as an Independent Prognostic Factor for the Survival of Triple Negative Breast Cancer Patients. J Cancer. 2016; 7: 1747-54.

27. Tamura T, Inagawa S, Hisakura K, Enomoto T, Ohkohchi N. Evaluation of serum high-density lipoprotein cholesterol levels as a prognostic factor in gastric cancer patients. Journal of gastroenterology and hepatology. 2012; 27: $1635-40$

28. Liu YL, Qian HX, Qin L, Zhou XJ, Zhang B. Serum LDL-C and LDL-C/HDL-C ratio are positively correlated to lymph node stages in males with colorectal cancer. Hepato-gastroenterology. 2011; 58: 383-7.

29. Han H, Guo W, Shi W, Yu Y, Zhang Y, Ye X, et al. Hypertension and breast cancer risk: a systematic review and meta-analysis. Sci Rep. 2017; 7: 44877.

30. Braithwaite D, Tammemagi CM, Moore DH, Ozanne EM, Hiatt RA, Belkora J, et al. Hypertension is an independent predictor of survival disparity between African-American and white breast cancer patients. Int J Cancer. 2009; 124: 1213-9.

31. Onitilo AA, Stankowski RV, Berg RL, Engel JM, Glurich I, Williams GM, et al. Breast cancer incidence before and after diagnosis of type 2 diabetes mellitus in women: increased risk in the prediabetes phase. Eur J Cancer Prev. 2014; 23 : 76-83.

32. Salinas-Martinez AM, Flores-Cortes LI, Cardona-Chavarria JM, Hernandez-Gutierrez B, Abundis A, Vazquez-Lara J, et al. Prediabetes, diabetes, and risk of breast cancer: a case-control study. Arch Med Res. 2014; 45: 432-8.

33. Li C, Hsieh MC, Chang SJ. Metabolic syndrome, diabetes, and hyperuricemia. Curr Opin Rheumatol. 2013; 25: 210-6.

34. Yamaoka K, Tango T. Effects of lifestyle modification on metabolic syndrome: a systematic review and meta-analysis. BMC Medicine. 2012; 10.

35. Jahangiry L, Shojaeizadeh D, Abbasalizad Farhangi M, Yaseri M, Mohammad $\mathrm{K}$, Najafi $\mathrm{M}$, et al. Interactive web-based lifestyle intervention and metabolic syndrome: findings from the Red Ruby (a randomized controlled trial). Trials. 2015; 16: 418 .

36. Bruno E, Gargano G, Villarini A, Traina A, Johansson H, Mano MP, et al. Adherence to WCRF/AICR cancer prevention recommendations and metabolic syndrome in breast cancer patients. Int J Cancer. 2016; 138: 237-44. 